\title{
Gender Based Environmental Justice
}

\section{Emilkamayana ${ }^{1}$, Nadiroh$^{2}$, and Achmad Husen ${ }^{3}$}

${ }^{1}$ Student of Environmental Education Department, Environmental Education Program, Universitas Negeri Jakarta, Indonesia

${ }^{2}$ Professor of Environmental Education Department, Environmental Education Program, Universitas Negeri Jakarta, Indonesia

${ }^{3}$ Lecture of Environmental Education Department, Environmental Education Program, Universitas Negeri Jakarta, Indonesia

\section{Abstract}

Increasing environmental pollution is causing a widespread negative impact. Therefore, a solution is needed to overcome the increasing environmental problems. One approach is to consider the question of justice for the environment itself. This approach is founded on the perceived relationship between the environment of activism and caring with distributive justice. Decision making processes with regards to environmental justice are frequently determined by the gender differences of the individual. Perceptions between women and men can be different in interpreting environmental conditions.

Corresponding Author:

Emilkamayana

emilkamayana@gmail.com

Published: 11 November 2020

Publishing services provided by Knowledge E

(c) Emilkamayana et al. This article is distributed under the terms of the

Attribution License, which

permits unrestricted use and redistribution provided that the original author and source are credited.

Selection and Peer-review unde the responsibility of the IC-HEDS 2019 Conference Committee.

\section{G OPEN ACCESS}

Women can be more sensitive in protecting the environment, while men are more logical. This article will discuss gender-based environmental justice to consider whether there is 'correct' perspective. This study uses a qualitative approach, reviewing and synthesizing journals related to Environmental Justice and Gender. As the fifth goal of sustainable development (SDGs), gender equality can increase the successful implementation of the principles of environmental justice.

\section{Keywords: gender, environmental justice, Sustainable Development Goals (SDGs)}

\section{Introduction}

Increasing environmental pollution caused a decrease in the quality of nature, both on land, sea, air and in the area where humans live themselves. This phenomenon was interrelated with each other, were due to melting glaciers at the poles caused loss of habitat for polar bears and other animals. Causing a decrease in environmental quality in all these polar regions. It was recently reported that more than 22 per cent of the world's plants is at risk of extinction, mostly due to habitat loss through the conversion of natural areas for agricultural use, including food and biofuel production. Then the latest phenomenon is the increasing level of pollution of plastic waste in the world. Where there is pollution of plastic pollution in the ocean as much as 40 per cent. It was found that there were deep and slow eddies in the oceans in the north pacific, 
south pacific, north Atlantic, south Atlantic and Indian oceans due to the gathering of plastic in the ocean currents. It has been shown that More than one million seabirds, 100,000 marine mammals, and many fish die in the North Pacific every year, either because they mistakenly eat this garbage or from being trapped in it and drowning [1]. Therefore, a solution is needed to overcome the increasing environmental problems by paying attention to justice for the environment itself. This argument applies to create a relationship between the environment of activism and caring with distributive justice, which is generally known as the environment of justice. Concerns related to raising some of the most difficult environments and public policy issues regarding the national political agenda and linking them with human rights issues. One of the main reasons why environmental justice raises concerns is that issues and related problems have the potential to have major public resource allocation decisions. Therefore, it is useful to differentiate at the outset between three broad public policy approaches to resource allocation [2]. As in the decision making that occurs in each country is determined by the gender differences of each individual. As in the difference in pro-environment behaviour in men and women, where women are more sensitive to using feelings in doing all their actions. Where as men use logic more in doing all kinds of actions. Researchers have also found that women show relatively stronger environmental care and behaviour than men [3]. That is why this article will discuss gender-based environmental justice to see how exactly the right perspective for the implementation of environmental justice following gender perspectives in solving environmental problems.

\section{Methods and Equipment}

\subsection{Methods}

In this paper, the literature review methods are used by reviewing and synthesizing journals relating to Environmental Justice and Gender [4]. Regarding to Templier, etc., al., [5], there are six steps to review articles in this method, namely: 1. developing the aim of research and research questions. In this step, researchers have to justify why they conducted their review, as a guideline to choose an appropriate design and provide the structure for the next step of the review process [6]. Defining the research questions in this research represent one of the most important steps to be taken in any study, such as an empirical study, a conceptual piece or a review paper. All authors reviews must necessarily exclude a multitude of work that lies near the boundary of their problem, even if they works that other reviews might choose to include. Therefore, 
in this research, researcher must define the key concept of their review to formulate the research questions. This article is focused on the concept of environmental justice and gender. 2 . seeking the current literature. This step start with identifying potentially relevant studies. When a review is focused with the findings in general, then it should ideally capture all the studies of interest. Researchers must select and justify a search strategy that is appropriate for research questions. 3. Screening for involvement. To claim that papers are appropriate with the research questions, researcher should ask themselves if each paper addresses the problem under inquiry and helps them to answer the reason question. 4. Assessing the quality of primary research. Researchers start in this step with looking the assessment tools such as the definition of the variables and their respective measures, the description of research method, and the results. Next, aggregating those results and selecting the papers through the interpretation of the findings and the recommendations for the future research. 5. Reducing data. This step, researcher gathered and extracted applicable information from each study. Extracting data for reviews usually include some thematic coding and conceptual classification, then making interpretations and judgement. 6 . The last step is analysing data with using appropriate techniques to make the information reasonable and to report the review results. Narrative and developmental reviews present the logical reasoning and justifications behind the findings. Authors have to organize, compare, collate, summarize, interpret the information previously extracted in order to suggest a new contribution to knowledge.

\section{Results}

Based on the results of reviewing and synthesizing the journal through the six steps it was found that Environmental sustainability is strongly supported by the role of each individual. The role of gender here also has a critical success factor in managing the environment in a better direction. Where, women are considered to be more active in only one specific perception of pro-environment actions related to behaviour (buying organic products, reducing vehicle use, sorting recycling) in private spaces, but not elsewhere related to public spaces (environmental membership groups and petition signatures, for example, are considered more male-dominated). So that it is expected that with the goal of sustainable development the 5th (fifth) SDGs on gender equality can accept the existence of women as policymakers who can become an innovation that is following the concept of environmental justice that does not differentiate race, gender, beliefs and culture. 


\section{Discussion}

Swim etc, al., [7] stated that policy arguments that focus on ethics and environmental justice are more associated with women than men. Because women are considered more sensitive in expressing these opinions. But, unfortunately, women are rarely involved in forum leaders or political leaders. This is because the average man prefers to focus on science and business rather than ethical and justice issues. Therefore men are more likely to be in a position of more dominant social influence. So it still looks that men are more dominant as leaders compared to women.

Peretz [8] states that men's involvement in anti-violence and women's rights movements has increased in the last few decades, which is in line with the goal of sustainable development of gender equality. Where in this study it was found that a group of activist groups had made changes to gender justice for men and women.

McGuinness, etc., al., [9] stated that CSR performance in some companies in the State of China is stronger in companies with CEO women can have a positive impact. Thus, women's leadership is very important to drive changes incorporate CSR. Besides that, the trust of female investors also prefers to entrust their funds to female CEOs as well, compared to male CEOs. Therefore companies with a greater female top management presence may be well-positioned to collect improved social and financial performance. Because greater social involvement supports market share and therefore adds value to the company.

Liu, [10] stated that gender diversity in companies, such as the presence of female board representatives and chief executive officers (CEOs) can reduce the frequency of environmental violations in companies when compared to homogeneous companies that only have male board representatives and chief executive officers (CEOs). So that the relationship between gender diversity has a positive impact on reducing environmental damage. This finding itself provides important new insights for investors, managers and policymakers in making women's leadership roles in public companies.

Irwin, etc., al., [11] stated that gender differences in environmental protection efforts especially in women, where they are more generous in charity to help the environment damaged when compared to men. So it was found that in general, research points to the conclusion that, compared to men, women are more compassionate, empathic, and oriented towards others.

Hein, etc., al., [12] stated that justice for gender is very necessary to understand every behaviour of both men and women. Where seen in women who are still a minority in some regions. So, with the change in sustainable development policies, women can 
be positioned in the same role as being able to obtain welfare for their lives. Because gender equality will improve environmental justice for the country itself, by taking into account the opinions of women as well.

Sitthikriengkrai and Porath, [13] stated that the impact of industrial pollution that occurred in Thailand caused environmental damage and losses for villagers in Thailand. So, environmental justice is needed in overcoming this problem. This environmental justice was initiated by the local NGO community that supports the community and the environment with goals that are in line with sustainable development. So that environmental justice is not only for nature but for the social environment such as the surrounding community which has an important role in supporting the welfare of the environment.

Velicu, [14] stated that criticism of economic growth where sacrificing nature without remembering its long-term impacts will harm the future of the environment. Thus, the application of environmental justice needs to be able to create local democracy and sustainable economic development. Environmental justice itself must remain an open goal that must be implemented for all parties involved. Thus, growing environmental justice can be dynamic, and continue to grow from year to year for welfare for development.

Davies, [15] stated that global concerns about environmental emissions standards and the cost of environmental compliance that many companies violate creates changes for environmental sustainability in harmony. The closure of factories that are not environmentally friendly is a form of implementation for environmental justice. Thus, green compliance with the environment will create environmental sustainability for the better. Although this is a challenge for the Government were a lot of debate in environmental management.

Dominelli [16] stated that the inclusion of environmental justice in contemporary social work practices as a way of promoting inclusive social work that meets some of the challenges of the 21st century. Such as the implications of environmental degradation and the impact of strengthening structural inequality in Sri Lanka after the 2004 Indian Ocean Tsunami, with environmental changes marked for the better, namely the application of environmental justice as the development of a multidisciplinary approach to the disaster that occurred. Thus, the application of environmental justice becomes very important for the future of the environment. Because environmental injustice itself is a form of community failure to ensure equitable distribution of Earth resources in meeting human needs. Therefore, together it is very important to provide the welfare of humans and planet Earth today and in the future for generations to come. 
Pulido, [17] stated that the importance of organizing environmental justice among multi-racial groups, as in black minority groups. Where in the US there are still injustices in his day - day. The application of inter-racial solidarity can reframe politics so that the application of environmental justice is following the applicable rules. Because the imbalance between rights and obligations should be balanced. Thus, the management of environmental policies must be following the conditions on the ground so that all parties get an equal and fair benefit of course. Our mapping of multiracial political solidarity shows that environmental justice can function as a convergence space for activists and intellectuals who want to think about the intersection between the conflicting parties.

Rawson and Mansfield, [18] stated that natural rights are a key element in better environmental management. Natural rights are described as a grassroots movement of various actors who oppose the anthropocentric principle. Where, nature also has the same rights as humans too, so they are also obliged to be protected. Thus, environmental justice here is the main key in achieving these natural rights by balancing indigenous relations with the environment. And in the end, every individual will maintain their rights and obligations towards that nature.

\section{Conclusion}

Gender is one of the determining factors for someone to behave in a pro-environment manner. Perceptions between women and men can be different in interpreting environmental conditions. Women can be more sensitive in protecting the environment, while men are more logical. However, it is unfortunate in some countries that men are still more dominant in determining environmental policies. Thus, women rarely participate in determining environmental policy. But over time the awareness of each individual created changes in regulations on gender equality. This can be seen in the fifth (fifth) SDGs, namely, gender equality. Where women also have the right to achieve sustainable goals. So with this goal, it is expected to create a balance of rights and obligations of both men and women, especially behaviour in managing their environment. Therefore, the importance of applying gender equality rules in each country to change the pattern of previous thinking in achieving social transformation for the better by taking into account the welfare of the environment following the principles of environmental justice.

\section{Funding}

This work was self-financed. 


\section{Acknowledgement}

The authors also would like to thankful to all the reviewers who gave their valuable inputs to the manuscript and helped in completing the paper.

\section{Conflict of Interest}

The authors have no conflict of interest to declare.

\section{References}

[1] White, R. (2013). Environmental Harm an Eco Justice Perspective. UK: Policy Press.

[2] Tarlock, A. D. (1994). City versus Countryside: Environmental Equity in Context. Fordham Urban Law Journal, vol. 21, pp. 461-494.

[3] Molina, M. A., et al. (2018). Does Gender Make a Difference in Pro Environmental Behavior? The Case of the Basque Country University Students. Journal of Cleaner Production, vol. 176, pp. 89-98.

[4] Green, B. N., Johnson, C. D. and Adams, A. (2006). Writing Narrative Literature Reviews for Peer-Reviewed Journals: Secrets of the Trade. Journal of Chiropractic Medicine, vol. 5, pp. 101-117.

[5] Templier, M and Pare, G. (2015). A Framework for Guiding and Evaluating Literature Reviews. Communications of the Association for Information Systems, vol. 37, pp. 112-137.

[6] Levac, D., Colquhoun, H. and O'Brien, K. K. (2010). Scoping Studies: Advancing the Methodology. Levac et al Implementation Science, vol. 5, pp. 1-9.

[7] Swim, J. K., et al. (2018). Gendered Discourse About Climate Change Policies. Global Environmental Change, vol. 48, pp. 216-225.

[8] Peretz, T. (2018). We're Not Equipped: The Paradox of Intersectional Failures in The Formation of Men's Gender Justice Groups. Journal of Men's Studies, pp. 1-21.

[9] McGuinness, P. B., Vieito, J. P. and Wang, M. (2016). "CSR Performance in China: The Role of Board Gender an Foreign Ownership. Journal of Corporate Finance, pp. $1-51$.

[10] Liu, C. (2018). Are Women Greener? Corporate Gender Diversity and Environmental Violations. Journal of Corporate Finance, pp. 1-66.

[11] Irwin, K., Edwards, K. and Tamburello, J. A. (2015). Gender, Trust, and Coorperation in Environmental Social. Social Science Research, vol. 50, pp. 328-324. 
[12] Hein, W., et al. (2016). Gender Justice and The Market: A Transformative Consumer Research Perspective. Journal of Public Policy \& Marketing, pp. 1-39.

[13] Sitthikriengkrai, M. and Porath, N. (2017). Lead Polluted Water Changed Our Lives: A Thai Karen Village's Quest for Environmental Justice. South East asia Research, vol. 25, issue 2, pp. 139-156.

[14] Velicu, I. (2019). De-Growing Environmental Justice: Reflections from Anti Mining Movements in Eastern Europe. Ecological Economics, vol. 159, pp. 271-278.

[15] Davies, P. A. (2014). Green Crime and Victimization: Tensions Between Social and Environmental Justice. Theoretical Criminology, vol. 18, issue 3, pp. 300-316.

[16] Dominelli, L. (2014). Promoting Environmental Justice Through Green Social Work Practice: A Key Challenge for Practitioners and Educators. International Social Work, vol. 57, issue 4 pp. 338-345.

[17] Pulido, L. (2018). Reimagining Justice in Environmental Justice: Radical Ecologies, Decolonial Thought, and the Black Radical Tradition. Environmental and Planning E: Nature and Space, pp. 1-23.

[18] Rawson, A. and Mansfield, B. (2018). Producing Juridical Knowledge: Rights of Nature or the Naturalization of right? Environmental and Planning E: Nature and Space, pp. $1-23$. 